\title{
Citrate Anticoagulation for Extracorporeal Circuits: Effects on Whole Blood Coagulation Activation and Clot Formation
}

\author{
A. Calatzis ${ }^{a}$ M. Toepfer ${ }^{b}$ W. Schramm ${ }^{a}$ M. Spannagla H. Schiffl ${ }^{b}$ \\ Divisions of a Hemostaseology and ${ }^{b}$ Nephrology, Medizinische Klinik Innenstadt, Ludwig Maximillians University, \\ Munich, Germany
}

\begin{abstract}
Dear Sir,
Adequate anticoagulation is a precondition for any effective hemodialysis therapy to prevent clotting in the extracorporeal circuit. While systemic anticoagulation with unfractionated heparin has been widely used, it is associated with several disadvantages, such as an increase in bleeding risk. Hemodialysis of patients who are at high risk for hemorrhages is complicated by a $10-30 \%$ incidence of bleeding [1,2]. Alternatives to conventional heparin anticoagulation that are designed to reduce bleeding complications include limited-dose heparinization, low-molecular-weight heparins, neutralization of heparin with protamine, prostacyclin infusion or saline-flush dialysis. Although the incidence of bleeding complications can be reduced, each of these methods has its own limitations [3, 4].
\end{abstract}

The use of regional citrate anticoagulation for hemodialysis and continuous renal replacement therapies in patients at high risk for bleeding offers unique advantages over other anticoagulation alternatives [3-6]. By virtue of chelating ionized calcium, citrate is a powerful anticoagulant. Free calcium ions are required for activation of coagulation (fig. 1) but are also reported to have concentration-dependent effects on clot polymerization [7-9].

Citrate anticoagulation is usually monitored by the determination of activated clotting time (ACT). However, this method is affected by factor deficiencies and other an- ticoagulants. Measuring ionized calcium by ion-selective calcium electrodes may be an inexpensive alternative way for monitoring citrate effects in regional citrate anticoagulation.

The aim of this study was to assess the dose-response relationship of citrate anticoagulation on coagulation activation and clot formation in whole blood. In addition, the value of direct determination of ionized calcium by ion-selective calcium electrodes for monitoring of citrate anticoagulation was evaluated.

Venous blood was taken from 6 healthy volunteers after informed consent and blood samples we immediately analyzed. Coagulation studies were performed with tubes containing anticoagulant citrate dextrose-A (ACD-A) in different amounts (0-5.65 $\mathrm{mmol}$ citrate/l of whole blood). ACD-A is an isotonic mixture of dextrose, citrate acid, and trisodium citrate $(38 \mathrm{mmol} / \mathrm{l}$ anhydrous citric acid, $75 \mathrm{mmol} / \mathrm{l}$ trisodium citrate) as commonly used by blood banks for blood sampling and cell storage.

Whole blood ACT was analyzed with a KC4-coagulometer (Sigma-Amelung, Lemgo, Germany) using kaolin as surface activator $(100 \mathrm{ng}$ of kaolin added to $0.3 \mathrm{ml}$ of whole blood). This test serves as a model for contact activation (intrinsic pathway) and determines the time until an initial formation of fibrin fibers is detected. Further, we performed thromboelastography (TEG) with a RoTEG analyser (Nobis, Endingen, Germany) [10]. With this test, fibrin formation kinetics and clot firmness are continuously assessed (fig. 2). Results are given as clot formation time (CFT; time from onset of clot formation until a clot firmness of $20 \mathrm{~mm}$ is attained) and maximum clot firmness (MCF). To reveal the effects of citrate on fibrin formation and clot polymerization, we performed clotting times and thrombelastograms using either kaolin as contact activator or the snake venom ecarin, which directly activates prothrombin independently from ionized calcium and earlier stages of the coagulation cascade $(0.2 \mathrm{U}$ of ecarin added to $0.3 \mathrm{ml}$ of whole blood) (fig. 3). [11]. Ionized calcium and blood $\mathrm{pH}$ were determined by ion-selective electrodes on a Synthesis 1720 analyzer (Instrumentation Laboratory, Kirchheim, Germany).

Studies using contact activation with kaolin revealed a dose-dependent inhibition of coagulation with increasing citrate concentrations (table 1). The correlation between concentrations of ionized calcium and clotting times revealed almost no anticoagulant effect when ionized calcium levels were $>0.50$ $\mathrm{mmol} / \mathrm{l}$, while clotting times showed a steep increase when calcium levels were further decreased (fig. 4). $5.65 \mathrm{mmol} / \mathrm{l}$ citrate induced clotting times of infinity in all samples. In contrast to these findings, in coagulation studies activated by ecarin, hemostasis parameters were not influenced at all (table 1).

\begin{tabular}{ll}
\hline KARGER & ( ) 2001 S. Karger AG, Basel \\
Fax +4161306 1234 $34-2766 / 01 / 0892-0233 \$ 17.50 / 0$ \\
$\begin{array}{l}\text { E-Mail karger@karger.ch } \\
\text { www.karger.com }\end{array}$ & $\begin{array}{l}\text { Accessible online at: } \\
\text { www.karger.com/journals/nef }\end{array}$
\end{tabular}

\author{
M. Toepfer, MD \\ Medizinische Klinik, Ludwig Maximilians University \\ Ziemssenstrasse 1, D-80336 Munich (Germany) \\ Tel +49 895160 2111, Fax +49 8951604406 \\ E-Mail toepfer@fbs.med.uni-muenchen.de
}




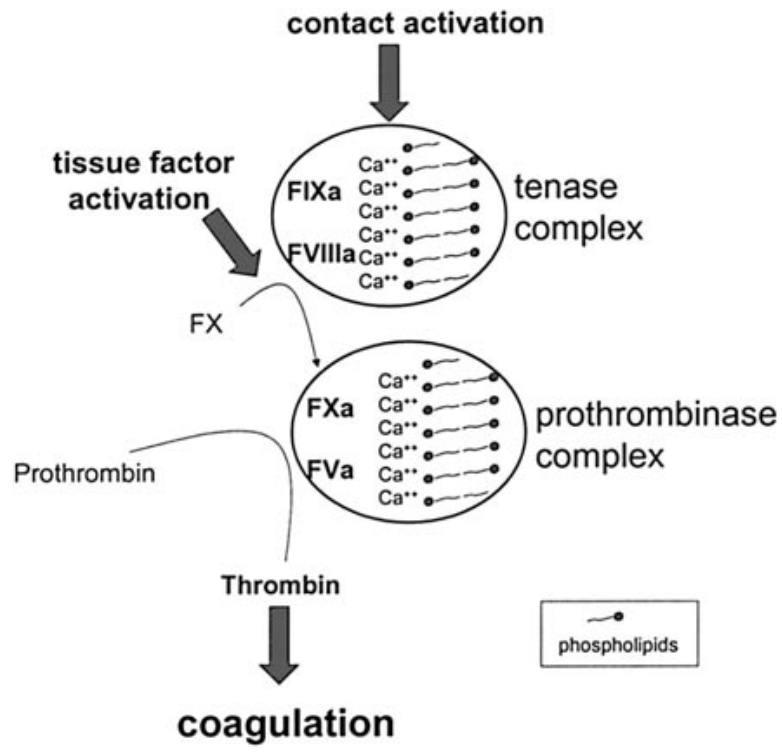

Fig. 1. The importance of ionized calcium in the activation of coagulation: ionized calcium is required for the formation of both tenase and prothrombinase complex, which lead to thrombin activation and finally to clot formation. Citrate acts by complexing ionized calcium and thus it inhibits the activation of coagulation.
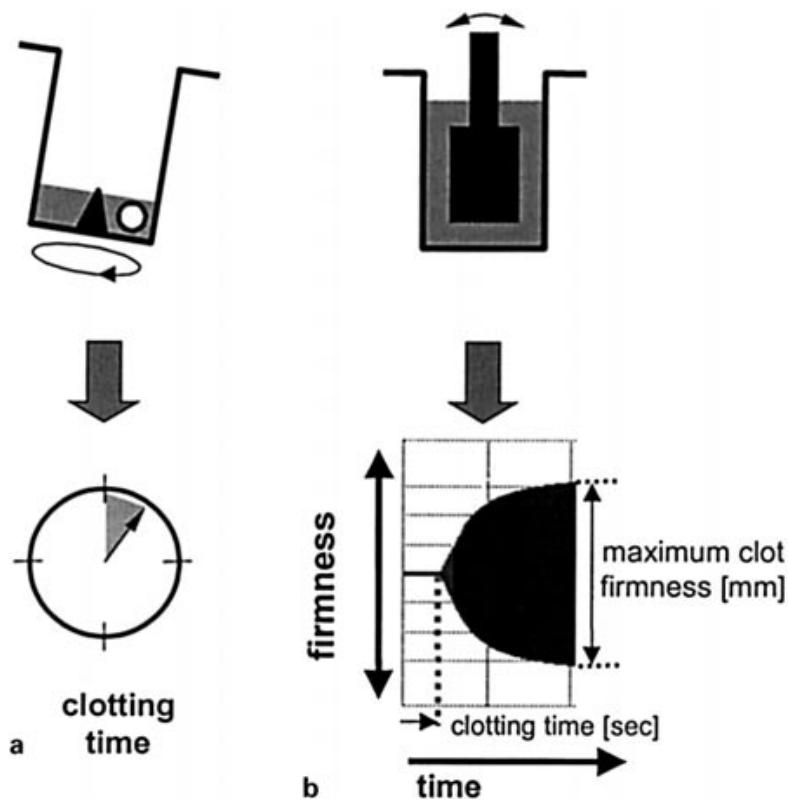

Fig. 2. Assessment of whole blood coagulation. a Coagulometric technique: The blood sample is placed into a rotating cup. The movement of a steel ball is detected magnetically. As soon as fibrin fibers are formed, the viscosity of the sample rises and the movement of the steel ball is stopped. By this technique the time interval from start of the test to the initial formation of the fibrin fibers is detected. b Thrombelastography: the blood sample is placed into a stationary cup. A cylindrical pin oscillates. The blood clot reduces the movement dependent on its firmness. With this technique, blood dynamics of clot formation and clot firmness are assessed.

Table 1. Clotting time, clot formation time and clot firmness of blood samples anticoagulated with increasing amounts of citrate

\begin{tabular}{|c|c|c|c|c|c|}
\hline $\begin{array}{l}\text { Citrate } \\
\mathrm{mmol} / \mathrm{l}\end{array}$ & $\begin{array}{l}\text { Ionized } \mathrm{Ca}^{2+} \\
\mathrm{mmol} / 1\end{array}$ & $\begin{array}{l}\text { Blood } \\
\text { pH }\end{array}$ & $\begin{array}{l}\text { KC4: clotting } \\
\text { time, } \mathrm{s}\end{array}$ & $\begin{array}{l}\text { TEG: clot } \\
\text { formation time, s }\end{array}$ & $\begin{array}{l}\text { TEG: clot } \\
\text { firmness, } \mathrm{mm}\end{array}$ \\
\hline \multicolumn{6}{|c|}{ Activation of clotting with kaolin } \\
\hline 0.00 & $1.18 \pm 0.05$ & $7.39 \pm 0.02$ & $101 \pm 9$ & $82 \pm 15$ & $65 \pm 4$ \\
\hline 1.13 & $0.67 \pm 0.07$ & $7.38 \pm 0.03$ & $108 \pm 13$ & $81 \pm 17$ & $66 \pm 5$ \\
\hline 2.26 & $0.40 \pm 0.04$ & $7.35 \pm 0.04$ & $157 \pm 51$ & $102 \pm 28$ & $63 \pm 4$ \\
\hline 3.39 & $0.28 \pm 0.03$ & $7.32 \pm 0.04$ & $327 \pm 175$ & $167 \pm 64$ & $56 \pm 6$ \\
\hline 4.52 & $<0.25$ & $7.29 \pm 0.04$ & $681 \pm 267$ & $423 \pm 245$ & $42 \pm 13$ \\
\hline 5.65 & $<0.25$ & $7.25 \pm 0.04$ & no clotting & no clotting & no clotting \\
\hline \multicolumn{6}{|c|}{ Activation of clotting with ecarin } \\
\hline 0.00 & $1.20 \pm 0.08$ & $7.40 \pm 0.03$ & $101 \pm 9$ & $74 \pm 16$ & $68 \pm 3$ \\
\hline 5.65 & $<0.25$ & $7.24 \pm 0.05$ & $104 \pm 8$ & $79 \pm 12$ & $67 \pm 6$ \\
\hline
\end{tabular}


Fig. 3. To evaluate the effect of citrate anticoagulation on clot formation and polymerization, coagulation studies were performed using either kaolin (contact activation) or the snake venom ecarin (direct prothrombin activation). Effects of citrate anticoagulation were assessed by clot formation time (coagulometric detection) or clot firmness (thrombelastographic analysis).

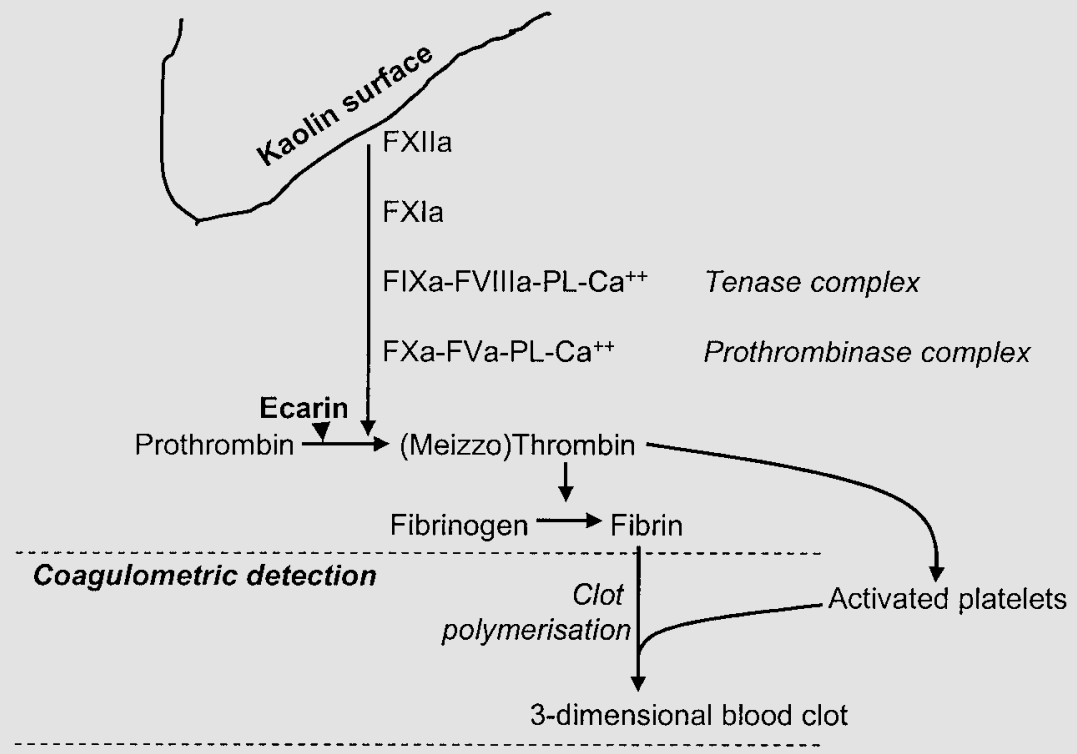

Thrombelastographic detection
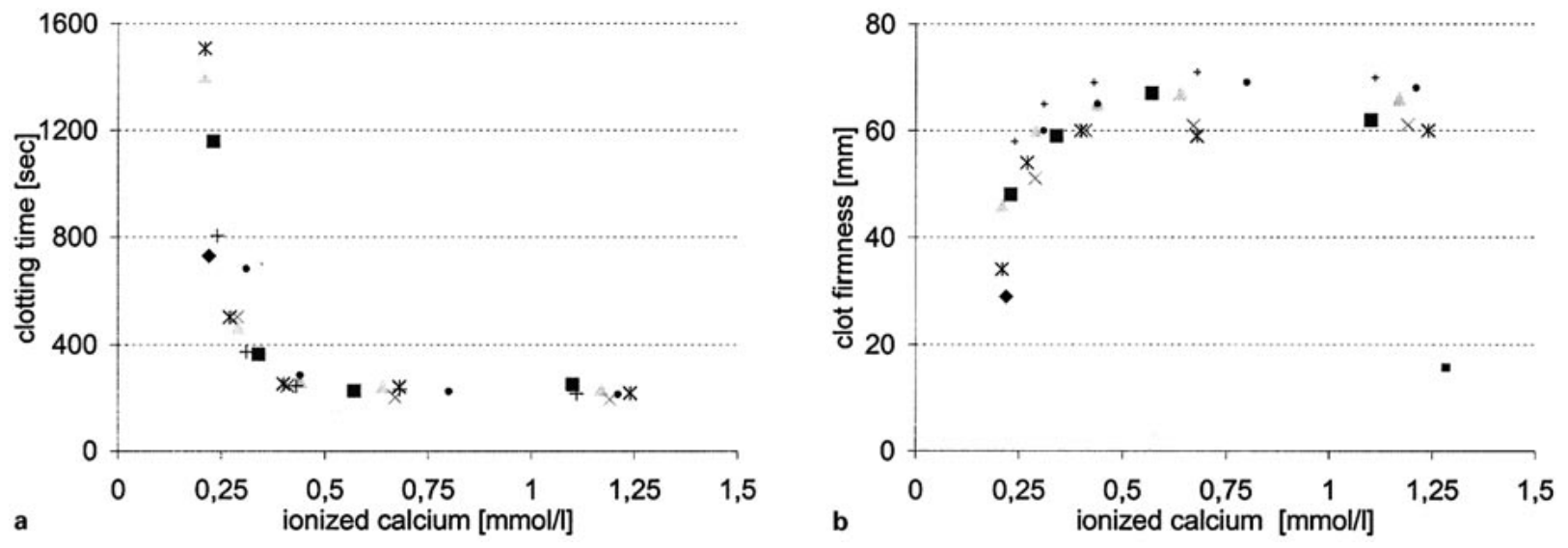

Fig. 4. Correlation of clotting time (a) and clot firmness (b) with ionized calcium. Coagulation triggered by contact activation (addition of kaolin to non-anticoagulated whole blood). 
In summary, citrate anticoagulation inhibits coagulation, in a dose-dependent manner. In concentrations used for regional citrate anticoagulation, citrate inhibits activation of coagulation but does not directly influence fibrin formation and clot polymerization. The clinically relevant effects of citrate anticoagulation rely alone on the disturbed formation of the calcium-dependent coagulation factor complexes. The anticoagulant effects of citrate can be monitored either by methods that quantify clot formation (i.e. ACT) or by direct assessment of ionized calcium levels. Measuring concentrations of ionized calcium by ion-selective electrodes can be used as an inexpensive and precise method of monitoring regional citrate anticoagulation.

\section{References}

1 Schwarz RD: Hemorrhage during high-risk hemodialysis using controlled heparinization. Nephron 1981;28:65-69.

2 Remuzzi G: Bleeding in renal failure. Lancet 1988;105:1205-1208.

3 Ward DM, Mehta RL: Extracorporeal management of acute renal failure patients at high risk of bleeding. Kidney Int 1993;43:237-244.

4 Pinnick E, Wiegmanson TE, Diederich DA: Regional citrate anticoagulation for hemodialysis in a patient at high risk for bleeding. $\mathrm{N}$ Engl J Med 1983;308:258-261.

5 Flanigan MJ, Pillsbury L, Sadewasser G, Lim VS: Regional hemodialysis anticoagulation: Hypertonic tri-sodium citrate or anticoagulant citrate dextrose-A. Am J Kidney Dis 1996;27: 519-524.

6 Janssen MJ, Deegens JK, Kapinga TH, Beukhof JR, Huijgens PC, van Loenen AC, van der Meulen J: Citrate compared to low-molecularweight heparin anticoagulation in chronic hemodialysis patients. Kidney Int 1996;49:806813.
7 Francis JL, Watson NJ, Simmonds VJ: The role of sodium citrate in the dysfibrinogenaemia of liver disease. Thromb Res 1984;34:187197.

8 Carr ME, Powers PL: Differential effects of divalent cations on fibrin structure. Blood Coagul Fibrinolysis 1991;2:741-747.

9 Sinauridze EI, Volkova RI, Krasotkina YV, Sarbash VI, Ataullakhanov FI: Dynamics of clot growth induced by thrombin diffusing into nonstirred citrate human plasma. Biochim Biophys Acta 1998;25:607-616.

10 Mallett SV, Cox DJ: Thrombelastography. Br J Anaesth 1992;60:307-313.

11 Kornalik F, Blomback B: Prothrombin activation induced by Ecarin - a prothrombin converting enzyme from Echis carinatus venom. Thromb Res 1975;6:57-63. 